\title{
8 \\ THE ROLES OF COMMUNITY-BASED NON- PROFITS IN THE CONTEXT OF COLLABORATIVE GOVERNANCE IN HONG KONG AND TAIWAN
}

José Chiu-C Chen and Helen K Liu

\section{Introduction}

Essential social programs, such as elderly care and assistance for low-income earners, have been introduced through community-based initiatives in Taiwan and Hong Kong. For example, over the past two decades, reforms to Taiwan's long-term care policy (Nadash \& Shih 2013) and the Community Care Stations project (Wang 2013; Wang 2016), and to Hong Kong's Lump Sum Grant Initiative (Lee 2005), have increased the role of community-based organisations (CBOs) in the provision of social services at the local community level (Lee \& Liu 2012; Liu 2019). These policies aim to provide personalised services and ease of access for the elderly or disabled (Hunter \& Ritchie 2007) by working with organisations that have strong connections with the community. This chapter stems from a need to explore how well these policies work and to investigate further 
the role of $\mathrm{CBO}$ in local communities and their impact on accountability and performance when used to deliver publicly funded services, especially in the context of moves towards collaborative governance.

Marwell (2009: 32) described CBOs as 'a particular kind of neighbourhood organisation: uniquely oriented to the external economic and political world, yet closely tied to specific geographic places and the local residents who are their constituents'. Chaskin and Greenberg (2015) have since provided a framework to examine the roles of $\mathrm{CBO}$ s in the context of governance, identifying three key roles: resource provision and allocation, representation, and deliberation. First, through contracting with local government agencies or foundations, $\mathrm{CBOs}$ may implement public policies by delivering essential services to local residents (Smith \& Lipsky 1993; Grønbjerg \& Salamon 2002). Second, by sitting on the boards of local committees or conducting advocacy activities, $\mathrm{CBO}$ s play the role of representing local residents (Marwell 2007; Mosley 2011); they may also negotiate decisions that are relevant to their communities' interests (Ostrander 2013). Third, by engaging local residents, CBOs provide a space for deliberation among them and influence the agenda for community affairs (Chaskin 2001; Chaskin \& Greenberg 2015).

As we move from the new public management (NPM) reforms towards more collaborative governance, existing studies on $\mathrm{CBO}$ s can help us understand community governance by reviewing how $\mathrm{CBOs}$ fulfil these three roles (Marwell 2007; Mosley 2011; Chaskin \& Greenberg 2015). This conceptual framework not only helps us to understand how CBOs operate and contribute to public policy, but also draws attention to the importance of the external relationships $\mathrm{CBOs}$ must build to contribute more broadly to governance issues in local communities. We ask research questions similar to those raised by Chaskin and Greenberg (2015), but in the context of Hong Kong and Taiwan. To what extent do the $\mathrm{CBO}$ serform and balance the roles of service delivery, advocacy, public engagement and political exchange? How do their external relationships affect their roles in the governance of the local community?

Following the methods used in Galaskiewicz's (1979) and Liu and Chen's (2015) studies, we selected 96 CBOs for in-depth, face-to-face interviews with directors or top managers in four urban poor communities in Taiwan and Hong Kong. The interview questions covered basic information about the organisation and its functions, its advocacy and public policy participation activities, and the CBO's external relationships with 
governments, funders and other non-profits. More specifically, our study examines the varied roles of these $\mathrm{CBO}$ s and explores factors that might influence their roles in Taiwan and Hong Kong, particularly in terms of their resources and external relationships.

\section{The development of collaborative governance in Hong Kong and Taiwan}

\section{New public management reforms}

Western and Asian countries have adopted NPM reforms with different focuses, depending on the political institutional arrangements, culture and socioeconomic conditions of the given country (Pollitt \& Bouckaert 2000). Previous studies have emphasised some common characteristics of the NPM reforms, including public-private partnerships, the introduction of competition and performance evaluations (Osborne \& Gaebler 1993; Hood 1995). Given the differences in political institutional arrangements and socioeconomic conditions between Hong Kong and Taiwan, the focus of NPM reforms has taken slightly different turns in both countries, including in terms of the emphasis on local community actors.

In Hong Kong and Taiwan from the 1990s, governments began to contract out to external service agencies, especially to community-based non-profits delivering various social services to local communities. The literature shows that non-profits can provide free or low-cost services to their beneficiaries, and they can act as service providers, advocates, value guardians and social capital creators for the community (Kramer 1981; Salamon 1997). The act of contracting out social services from the government to non-profits shifts the mode of service provision from uniform and standard systems to systems with greater flexibility and variety (Ferlie, Ashburner, Fitzgerald \& Pettigrew 1996). In these more flexible systems, differently sized agencies can be selected to address the varying demands for the types of public services required (Gruening 2001: 7). From the government's perspective, contracting out has the additional advantage of attracting professionals who are not otherwise available to participate in service delivery (Christensen \& Lægreid 2001: 83). 
The selection of not-for-profit partners is a challenge in managing partnerships. To ensure the quality, efficiency and accountability of services, the government introduced competitive bidding to select potential community partners. In Hong Kong during the 1990s, the Social Welfare Department introduced the Lump Sum Grant Initiative, a short-term competitive grant, to replace the long-term Standard Unit Cost Model grant (Lee 2005; Lee \& Liu 2012). Non-profit organisations that receive funding to provide various social services (such as social security; family and child welfare; clinical psychology; rehabilitation; and aged, youth and community services) must prove that they meet established program goals before they can receive additional grants. In Taiwan, a competitive bidding process was created to select community partners to carry out social, youth, elderly, health and other community services on behalf of local governments (Wu 2011).

Contracting non-profits are required to demonstrate their performance in meeting set targets and goals (Ferlie et al. 1996). The performance approach results in a list of measurable outcomes to evaluate social services and a high degree of professionalism in the workforce (Meyer \& Zucker 1989). For instance, in Hong Kong, a series of public management reforms in the 1990s - including a service performance monitoring system, service quality standards, and funding and service agreements - were created as guidelines to measure and monitor non-profits that received government funding (Painter 2005; Lee \& Liu 2012; Wang 2013). In Taiwan, nonprofit organisations were also required to be accountable and provide evidence-based outcomes to demonstrate their performance before being able to secure government contracts (Wu 2011).

\section{Moving toward collaborative governance}

Collaborative governance is an approach in which the government openly and inclusively involves various stakeholders in dynamic processes of communication and adjustment to work toward a common goal (Ansell 2003; Emerson, Nabatchi \& Balogh 2012). Jing and Hu (2017) argue that contractual relationships between the government and nonprofits under NPM evolve naturally into collaborative governance among stakeholders in the provision of social services. While the NPM reforms in both Hong Kong and Taiwan involved competition and performance evaluation, different policies and systems emerged over time to collaboratively build the capacities of the community-based non-profits to carry out social services on behalf of governments. 
In Hong Kong, under the influence of NPM, the Social Welfare Department prompted local community centres to deliver integrated services through so-called one-stop service centres. These centres provide specialised integrated services, including to children, youth and the elderly; in-home care; mental wellness; and family services. These centres are designed to integrate multiple local government agencies and nonprofits into one unit and allow clients to access specialised services at a single location. This change has also created a top-down system and entails a greater dependence of the community-based non-profits on local government welfare agencies.

In Taiwan, as a continuous initiative since 1997, the government has introduced a series of reforms to establish long-term care management centres in certain districts leading to the Promotion of Community Care Development Act (Wu 2011). The previous long-term care reforms established a foundation for the development of a 10-year Phase 1 and Phase 2 long-term care program with the aim of building community capacity through contracting directly with community-based nonprofits to deliver essential social services (Wu 2011). Community care in Taiwan has its roots in the development of long-term care reforms with resources flowing to community actors who play essential roles in providing direct social services to residents. The focus of community care and home care is a bottom-up system requiring city governments to build and strengthen the capacity of CBOs. This system is similar to community care systems in other countries, such as that operating under the United Kingdom's National Health Service and Community Care Act 1990 (Ackroyd, Kirkpatrick \& Walker 2007).

While the structures of community networks might be different, the governments in Hong Kong and Taiwan both face governance challenges, because managing collaborative systems requires the administration to go beyond traditional boundaries (Kettl 2006). Resolving citizens' needs requires the collaboration or cooperation of multiple agencies, sometimes from different sectors. This means that the government, the private sector and the $\mathrm{CBO}$ s must be adaptive and able to manage complex relationships in the institutional environments where they operate (Agranoff \& McGuire 1998). Previous studies have focused on how governments address emerging collaborative initiatives and integrated services (Agranoff \& McGuire 1998; Liu \& Chen 2015). Here, we focus on the roles of $\mathrm{CBO}$ in implementing collaborative initiatives and integrated services in Hong Kong and Taiwan. 


\section{The roles of CBOs in implementing collaborative governance}

Studies on CBOs illustrate how they fulfil various roles in carrying out social services and engaging the public in a complex institutional environment (Osborne 2006; Marwell 2007; Mosley 2011; Chaskin \& Greenberg 2015). Chaskin and Greenberg (2015) provide a framework for illustrating the roles of CBOs in the context of governance. First, after contracting with the local government agencies or foundations, CBOs carry out policies and deliver essential services for local residents (Smith \& Lipsky 1993; Grønbjerg \& Salamon 2002).

Second, by sitting on the boards of local policy committees or conducting advocacy activities, CBOs represent local residents (Marwell 2007; Mosley 2011) and negotiate decisions that are relevant to their communities' interests (Ostrander 2013). For instance, CBOs often have an agenda with regard to local affairs and wish to resolve their issues of concern through a particular political channel (Crenson 1983). Sometimes, the government intentionally builds relationships with reputable CBOs, seeking to engage a particular target group of residents and build a participatory system through those CBOs (Berry, Portney \& Thomson 1993). Kuan, Lee and Hsieh (2006) also found that CBOs in Taiwan act in accordance with residents' interests to address local issues, such as development, unemployment and social inclusion. Following some CBOs' successful influence over local policies, the government reached out to the $\mathrm{CBO}$ s for regular consultation.

Third, by engaging local residents, $\mathrm{CBO}$ s provide a space for deliberation among them and for setting agendas for community affairs (Chaskin 2001; Chaskin \& Greenberg 2015). While the nature and scope of the deliberation varies across communities and types of CBOs, often a wide range of community actors are engaged to participate (Chaskin $\&$ Greenberg 2015). The physical presence of the CBOs' offices in the local community can allow residents to get together through local activities and discuss various issues (Marwell 2004). Kuan et al. (2006) also found that the governing boards of CBOs are composed of local volunteers, enabling deliberation on community issues to take place within the $\mathrm{CBO}$ setting.

Chaskin and Greenberg's conceptual framework enhances not only the understanding of the different roles of CBOs, but also addresses how their construction of different external relationships might influence governance 
issues in local communities. Marwell's $(2004,2007)$ community studies further elaborate the roles of CBOs in the context of governance. Building on other studies (Chaskin 2001; Chaskin \& Greenberg, 2015), Marwell's (2004) work argues that CBOs generate greater contract revenue by adding electoral politics to their traditional roles of providing services and building communities.

This model produces a new kind of CBO: the political machine (Marwell 2004, 2009; Liu 2019). By reciprocally distributing services to residents and binding residents to the organisation, political machine CBOs create reliable voting constituencies for local elected officials. These officials trade these constituencies at higher levels of the governmental system and steer government human service contracts to favoured CBOs. This suggests that some CBOs might intentionally form relationships with local elected officials to obtain funding and resources, especially those CBOs that have closer and more direct relationships with community residents.

\section{Network roles under collaborative governance}

In addition to understanding the functional roles of CBOs, Ansell (2003) argues that it is necessary to measure how organisations are embedded within a broader collaborative governance structure. Granovetter (1985) explains how embeddedness in social relations allows exchange among actors within the system, with less dependence on organisational hierarchy. Network embeddedness also enhances the capacity of organisations to make exchanges through relational and informal mechanisms, such as trust, reciprocity and norms (Powell 1990; Gulati \& Gargiulo 1999; Uzzi 1996; Ansell 2003). The social embeddedness of organisations is associated with the construction of social capital through a horizontal network among organisations that engage the public actively in public affairs (Putnam 1993).

The social embeddedness of an organisation refers to its embedding within a set of social relationships or networks (Ansell 2003). The more central an organisation is within a set of social relationships in a network, the more it is embedded in the network (Gulati \& Gargiulo 1999). Network theory uses centrality as a measure of organisations' embeddedness. Centrality can be measured in several ways (Freeman 1979). Degree centrality refers to the number of ties an organisation sends to others (outdegree) or receives from others (indegree). This captures the importance of the organisation. More 
specifically, a high outdegree indicates that an organisation is networking actively with other organisations while a high indegree indicates that an organisation is prestigious or powerful, with others seeking partnership with it. Previous research suggests the following distinct roles, divided according to the degree of centrality: 'prestigious organisation', 'boundary spanner' and 'peripheral organisation'.

While previous studies have laid a strong theoretical foundation for understanding the roles ofCBOs in the context of collaborative governance, as yet we know little about the roles of CBOs in Hong Kong and Taiwan, which face similar transitions from NPM's competitive model to new governance's emphasis on collaboration. This study applies case study and social network analysis to examine how CBOs in Hong Kong and Taiwan perform and balance the roles of service delivery, advocacy, public engagement and political exchange, as well as the influence of external relationships on their roles.

\section{Methods and data}

According to Yin (2004), a unique and relevant case might not be representative in a given research site, but it could serve a purpose by advancing theory through the understanding of a specific phenomenon. Consistent with this view, this study focuses on four communities in the poorest districts of the cities, namely Kwun Tong and Shek Kip Mei (Hong Kong), Taipei and Old Train Station (Taiwan). For data collection, following methods in Galaskiewicz's (1979) and Liu and Chen's (2015) studies, we selected 96 directors or top managers of CBOs in the four urban poor communities for in-depth, face-to-face interviews. The subjects of the interview questions included organisational functions and basic organisational information, advocacy and public policy participation activities, and the external relationships of the CBOs with governments, funders and other non-profits.

Our primary focus was to examine partnership selection among CBOs, following Provan and Milward's $(1991,1995)$ procedures. To assist our examination of relationships, we created a table listing all the $\mathrm{CBO}$ within each of the relevant communities and asked the respondents to select the organisations with which they had working relationships, and to identify the direction of the relationship. To illustrate the relationships, four sociomatrices with multiple relationships were developed. We did 
not assume symmetrical relationships for the sociomatrix representing partnership selection because the directional ties allowed us to examine the power dynamics (White, Boorman \& Breiger 1976; Ansell 2003). To illustrate the structure of this network, we adopted a network analysis technique to visualise the four networks and their associated characteristics (Wasserman \& Faust 1994).

\section{Results}

\section{The characteristics of social service provisions in Hong Kong and Taiwan}

\section{Professionalism and competition}

There is increasing demand on CBOs to deliver social services in Hong Kong and Taiwan, both to respond directly to the actual needs of society and to meet the demands for services that are being passed on by government. Our findings on the roles of the CBOs in service provision are consistent with existing findings on non-profits in general (Lee \& Liu 2012; Xian, Kuan \& Lu 2009). For instance, in a study of large nonprofit databases and their missions, Xian et al. (2009) found social service organisations that received government funding serve mainly in the social welfare and education sectors and with increased professionalism in service delivery. Our survey found a trend also for those CBOs that focus on social provision to be more professional. For instance, in Hong Kong, most CBOs receiving government funding have joined the Hong Kong Council of Social Service, which sets the standard for the provision of social services in Hong Kong (Lee 2005).

Furthermore, our study found that most of the CBOs in Hong Kong and Taiwan have small- and medium-size funding amounts, as they are frontline centres and receive only limited support from their local headquarters. More than half of these organisations self-reported from our open-ended questions about financial difficulties and lack of managerial experience, small-scale, limited mobilisation ability, inadequate ability to sustain operations, confined quarters, lack of communication skills for coordinating with other organisations, insufficient scale of participation or intervention, and deficient understanding of their social and economic environment. The larger $\mathrm{CBOs}$ have greater capacity to secure funding, despite the competitive environment. 


\section{Political influence and social embeddedness}

A previous study shows that most of the CBOs studied in Hong Kong do not carry out advocacy activities or have political involvement (Centre for Civil Society and Governance 2010), whereas the CBOs in the two cities in Taiwan have greater political activity and engage residents in signing petitions and joining organised protests (Lin, Chuang, Liu \& Hwang 2012). Consistent with our findings, but with some variations (see 'Discussion' below for details), many small local or regional organisations have appeared in recent years, forming an indispensable grassroots force in different regions. Given their size, CBOs in Taiwan must mobilise networks to gain support from the community for petitioning or advocacy activities. Thus, this type of $\mathrm{CBO}$ tends to form external relationships with actors of diverse backgrounds.

\section{Network roles of non-profits}

Next, by analysing social networks in four communities (two in Hong Kong and two in Taiwan), we examined degree centrality as a measure of organisations' embeddedness (Ansell 2003). As explained above, degree centrality refers to the number of ties an organisation sends to others (outdegree) or receives from others (indegree). We classify the roles that $\mathrm{CBO}$ play based on their number of outdegree and indegree ties with other CBOs as partners in local communities. These roles can be described as prestigious, boundary spanning and peripheral CBOs (Table 8.1). We then examine the network roles and the average organisational characteristics of these network types across the four communities (summarised in Table 8.2).

Table 8.1. Four social service networks in Hong Kong and Taiwan and their network roles as measured by degree centrality

\begin{tabular}{|l|c|c|c|c|}
\hline Roles & $\begin{array}{c}\text { Sau Mau Ping, } \\
\text { Hong Kong }\end{array}$ & $\begin{array}{c}\text { Sham Shui Po, } \\
\text { Hong Kong }\end{array}$ & Beitou, Taipei & $\begin{array}{c}\text { Central } \\
\text { Taicheung }\end{array}$ \\
\hline Prestigious & $27.6 \%$ & $19 \%$ & $32 \%$ & $20 \%$ \\
\hline Boundary & $41.4 \%$ & $33.3 \%$ & $28 \%$ & $40 \%$ \\
\hline Peripheral & $31 \%$ & $47.6 \%$ & $40 \%$ & $40 \%$ \\
\hline
\end{tabular}

Source. Surveys conducted by authors 


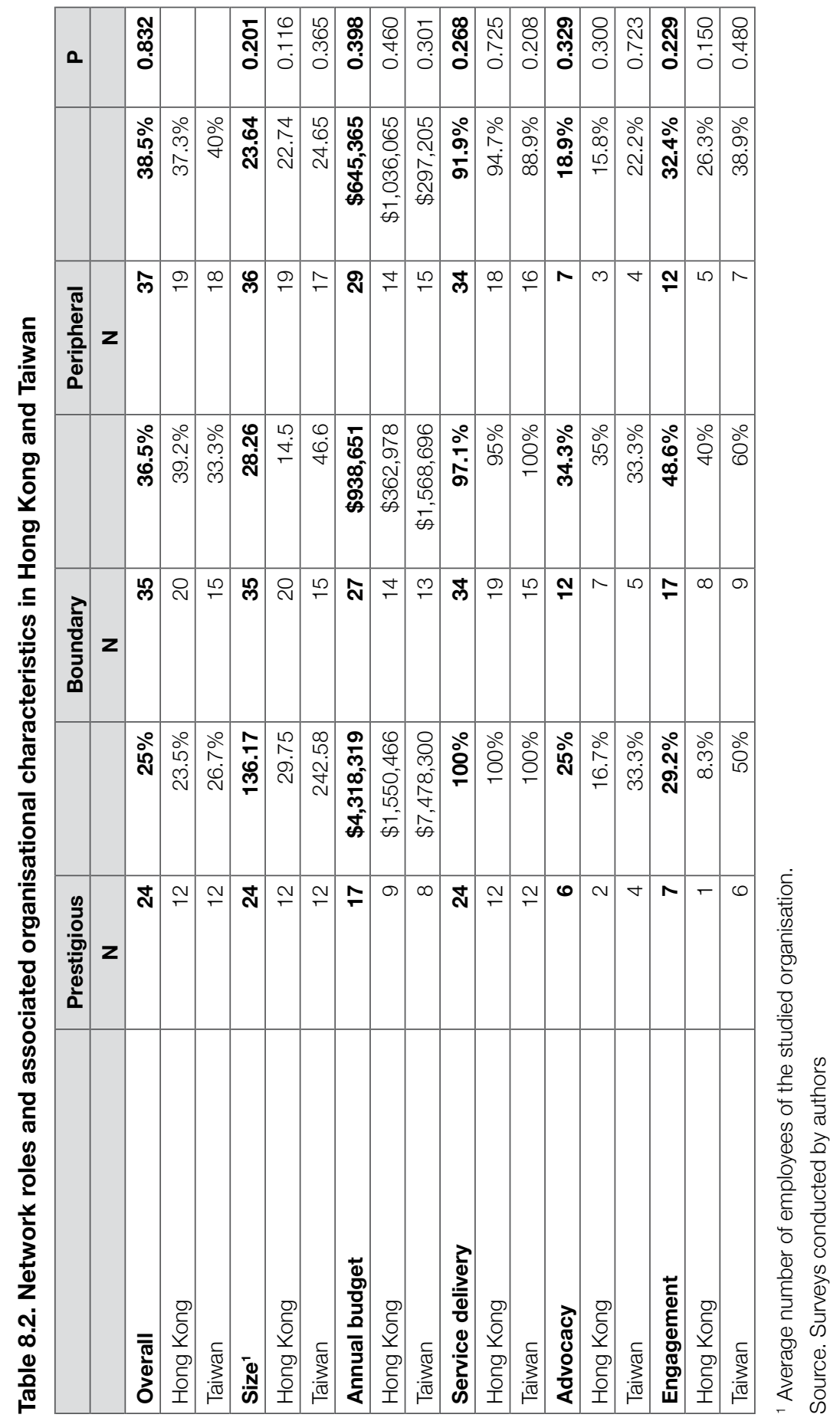




\section{Prestigious CBOs}

\section{Prestigious CBOs have stronger ties with government and sufficient resources but are less flexible}

In social network analysis, prestige can be measured by the indegree number. In other words, the higher its indegree number, the more prestigious the given $\mathrm{CBO}$ is. Our data shows that about 25 per cent of CBOs are prestigious within their community networks (Table 8.1). In Hong Kong and Taiwan, we find that service delivery is the primary function of prestigious $\mathrm{CBO}$ s and they tend to collaborate with other $\mathrm{CBOs}$ that are also primarily service providers, and they are not particularly involved in political activities, such as petitions, advocacy or citizen engagement (Table 8.2).

One explanation for this could be that $\mathrm{CBO}$ s receiving significant government funding must follow service quality guidelines and remain non-partisan. Thus, they organise events and exchange resources within their existing networks but are reluctant to share their resources with actors outside this system. They enjoy not only reliable funding from the government, but also a high level of prestige, as evidenced by the many ties that they enjoy. There are, however, few reciprocal ties from this type of $\mathrm{CBO}$ to others. As a result, the integrative system designed originally by the government to build networks in the community has become a more inclusively networked social service system.

\section{Boundary spanners}

\section{Boundary spanners connect with everyone but have less resources and political motivations}

The term 'boundary spanner' refers to those who have connections with different types of actors within communities. For instance, a boundary spanner would not only have a higher degree of outdegree relationships but also connect with different types of organisations according to the nature of their service. In our data, we found about 36.5 per cent of $\mathrm{CBO}$ are boundary spanners. The data also shows that boundary spanners are, moreover, mostly politically affiliated (either with a local district councillor/representative or they are founded by politicians) and tend to have more ties with CBOs of diverse backgrounds. For instance, in Hong Kong, district councillors and politically affiliated CBOs serve a bridging role in poor urban communities because they actively build relationships with different community members. 
As in Marwell's (2004) study, the current study identified an exchange relationship among local politicians, politically affiliated $\mathrm{CBO}$ and other informal neighbourhood associations. Politically affiliated groups build working relationships but are also keen to gain resources and access to local residents to expand their political interests. This was especially observed in Hong Kong (Liu 2019) and is similar to the case in Taiwan, where local elected representatives work with specific $\mathrm{CBO}$ s to deliver meal services and perform elderly visits in exchange for gaining potential political support from community residents, as reported by the local representative office in Beitou, Taipei. Political interference, however, was reflected more clearly in our open-ended survey in Hong Kong, where the interviewees noted that politics represented a major obstacle to building mutual trust and understanding in their community (see 'Discussion' below).

\section{Peripheral CBOs}

\section{Peripheral CBOs have fewer connections with actors in their communities}

Our analysis showed that 38.5 per cent of the CBOs are peripheral, based on their network connections. These CBOs are either smaller or informal, have fewer connections with other CBOs and do not occupy an important position within their own community networks; they also are less involved in advocacy (Table 8.2). Such informal CBOs are, however, often gathering points for local residents and provide access to a specific group with a particular ethnicity or special need, such as the deaf, single mothers or private community foundations. Such CBOs tend to have fewer resources (see Table 8.2) and are reached by the politically affiliated $\mathrm{CBOs}$ rather than the social welfare CBOs.

In sum, the preliminary results show that $\mathrm{CBOs}$ serve the roles of social service provision and allocation, representation and deliberation, yet differences between Taiwan and Hong Kong exist. For instance, the CBOs in Hong Kong reported that they play a minimal role in advocacy and policy participation, while those in Taiwan reported a relatively higher degree of advocacy and policy participation. This study explores the extent to which CBOs are involved in the policymaking process or in advocacy activities and how this varies depending on their resources, community influence and external relationships with government. In doing so, the study shines some light on the implications for community governance in Hong Kong and Taiwan. 
A few limitations should be noted before the findings are discussed. First, the empirical cases selected for this study are based on theoretical relevance. The target communities do not represent typical communities. Instead, our research team chose low-income communities at each site. This narrows the application of our findings, but it allows us to examine the roles of CBOs in serving the poor.

\section{Discussion}

\section{Differences between Hong Kong and Taiwan}

\section{Top-down versus bottom-up approach}

Due to social and political differences, the governance structures of the community networks in Hong Kong and Taiwan were created differently. One major difference is Hong Kong's more top-down rather than bottom-up structure. As noted, in the early 2000s, the Hong Kong Government established service integration centres to provide onestop services for children, youth and the elderly; in-home care; mental wellness; and family services. These centres integrate local government agencies and non-profits into one unit and allow clients and service users to access different specialised services at one location. For instance, multiple agencies that we interviewed in Hong Kong were co-located in the same office building and provided services to the same low-income families. The government in Hong Kong allows rent deduction for nonprofits that choose to be located on public housing estates so their clients can readily access services. Because of policy incentives and geographic convenience, both of the communities studied in Hong Kong presented a top-down structure of social service provision.

In Taiwan, NPM reforms in welfare policy took a different turn and put more emphasis on community care and community-building. For instance, before the 2000s, a 10-year Phase 1 and Phase 2 long-term care program was intended to build community capacity by contracting directly with community-based non-profits to deliver essential social services (Wu 2011). Instead of establishing hub centres, Taiwanese policies, like those on long-term care and community care, focused on capacity-building and service-training programs for the local CBOs. Furthermore, through a series of decentralised funding processes and 
resource decisions for local city and district governments, the amendment of some service contracts to make them more manageable in terms of scope and boundaries allowed CBOs to bid for government contracts.

\section{Engagement versus advocacy}

To increase its role in government coordination, the Hong Kong Government actively engages local CBOs. Table 8.3 shows the differences in engagement channels utilised by CBOs in Hong Kong and Taiwan. Surprisingly, CBOs in Hong Kong reported a higher percentage of government engagement through sitting on central or local government boards/committees and participation in public consultation or government panels. For instance, we found a higher percentage (37 per cent) of CBOs in Hong Kong have a representative on local coordinating committees than in Taiwan (13 per cent).

Table 8.3. Differences in the engagement channels utilised by CBOs in Hong Kong and Taiwan

\begin{tabular}{|l|c|c|r|c|c|c|c|}
\hline & \multicolumn{2}{|c|}{ Hong Kong } & \multicolumn{2}{c|}{ Taiwan } & \multicolumn{2}{c|}{ Total } & \\
\hline Engagement channels & N & \multicolumn{1}{c|}{$\%$} & \multicolumn{1}{c|}{ N } & \multicolumn{1}{c|}{$\%$} & N & \% & P \\
\hline Government board/committee & 11 & 21.57 & 9 & 20.45 & 20 & 20.83 & 0.000 \\
\hline Government panel/consultation & 17 & 33.33 & 12 & 27.27 & 29 & 30.21 & 0.000 \\
\hline Regional committee & 19 & 37.25 & 6 & 13.64 & 25 & 26.04 & 0.000 \\
\hline Public consultation & 15 & 29.41 & 10 & 22.73 & 25 & 26.04 & 0.000 \\
\hline
\end{tabular}

Source. Surveys conducted by authors

There are two possible reasons for this disparity. First, the development of social service provision differs historically between Hong Kong and Taiwan. In Hong Kong, beginning in the British colonial period, the government adopted a cooperative strategy and invited large and influential non-profit organisations to sit on government committees (Lee 2005). Hong Kong district councils were designed to cooperate with influential non-profits and they continue to play an essential coordinating role in local communities (Leung 2010). These committees are an important communication channel between the government and the non-profit sector. Taiwan's political transformation from an authoritarian state to a democratic system resulted in non-profits emerged more gradually.

Second, and perhaps related to the different histories, CBOs in the two jurisdictions have different approaches to, and use different means of, engagement and advocacy (see Table 8.4). In Taiwan, CBOs are more 
involved in advocacy (only 23 per cent report that they did not conduct advocacy activities, compared to 59 per cent in Hong Kong), and they use a wider range of channels. The CBOs in Hong Kong advocate mainly through their member networks (29 per cent), with limited use of other means such as the internet (16 per cent) and street petitions (14 per cent). $\mathrm{CBOs}$ in Taiwan relied less on their member networks (16 per cent) and much more on the internet ( 52 per cent), TV ads ( 20 per cent), public media (18 per cent) and mailed advertisements (18 per cent). Both made some use of street petitions.

Table 8.4. Differences between CBOs in Hong Kong and Taiwan in their adoption of advocacy methods

\begin{tabular}{|l|r|c|r|r|r|r|c|}
\hline & \multicolumn{2}{|c|}{ Hong Kong } & \multicolumn{2}{|c|}{ Taiwan } & \multicolumn{2}{|c|}{ Total } & \\
\hline Advocacy methods & N & \multicolumn{1}{c|}{$\%$} & \multicolumn{1}{c|}{ N } & \multicolumn{1}{c|}{$\%$} & \multicolumn{1}{c|}{ N } & \multicolumn{1}{c|}{$\%$} & P \\
\hline Member network & 15 & 29.41 & 7 & 15.91 & 22 & 22.92 & 0.000 \\
\hline Email/phone text & 3 & 5.88 & 7 & 15.91 & 10 & 10.42 & 0.000 \\
\hline Social media & 8 & 15.69 & 23 & 52.27 & 31 & 32.29 & 0.000 \\
\hline Direct mail & 1 & 1.96 & 8 & 18.18 & 9 & 9.38 & 0.000 \\
\hline Street ads & 7 & 13.73 & 5 & 11.36 & 12 & 12.50 & 0.000 \\
\hline TV ads & 2 & 3.92 & 9 & 20.45 & 11 & 11.46 & 0.000 \\
\hline Public media & 1 & 1.96 & 8 & 18.18 & 9 & 9.38 & 0.000 \\
\hline Others & 10 & 19.61 & 11 & 25.00 & 21 & 21.88 & 0.000 \\
\hline
\end{tabular}

Source. Surveys conducted by authors

\section{The implementation challenges of collaborative governance}

The development of effective collaborative governance systems in local communities poses a challenge to policymakers as well as to the $\mathrm{CBO}$ that implement them. Previous studies have focused more on finding the right combination for collaboration to be effective. As discussed previously, governments have transformed and redesigned social service provisions to be more collaborative and effective, creating one-stop services in the United States, community care in Taiwan, the No Wrong Door policy in the United Kingdom, and integrative service in Hong Kong. This study finds that frontline CBOs struggle to balance their roles of service provision, engagement, advocacy and creating relationships with others to gain additional resources and information to survive in 
the competitive environment. By understanding the role played by $\mathrm{CBO} s$ in implementing collaborative governance in the local community, our findings reveal a number of challenges.

\section{Resource-distribution asymmetry}

Under the NPM reforms, governments adopted a competitive bidding process to allocate resources and funding. Our interviews show, however, that resources and funding are allocated mainly to larger and more established non-profits. These CBOs have extended networks and affiliated non-profits that provide similar services or share the same religious or political backgrounds. These clusters of medical and elderly service organisations make the competition for contracts more difficult for newly established non-profits, because it is difficult for them to access clients and build the capacity to bid for contract work. For instance, interviewees from organisations that were established in Hong Kong after 2000 reported difficulty in obtaining service contracts from the government because their client base was smaller than that of larger organisations. To be competitive, these new service organisations had to emphasise their innovativeness and personalised services for the elderly.

\section{Lack of coordination with diverse non-profits}

When policy requires them to extend their working boundaries to be more accessible to clients, CBOs are likely to seek less costly relationships or form networks with similar organisations rather than the most effective or efficient ones. Such less costly relationships with similar organisations are usually confined within the existing boundaries of missions, capacities, resources, responsibilities, accountability and networks, as Kettl (2006) found. Not surprisingly, even well-intended policies cannot be accomplished without taking into account the costs of building relationships with organisations with different networks.

\section{Political involvement creates distrust among CBOs}

A surprising finding from our open-ended questions was the negative aspect of political engagement. The negative effects of the political involvement of $\mathrm{CBO}$ s are particularly significant in Hong Kong. Some interviewees reported that politics is a major obstacle to building mutual trust and understanding in their community. The following observation was reported from an interview in Hong Kong with a librarian at a local public library: 'An organisation's political partners reduce opportunities for cooperation.' 
This perception hinders the development of networking relationships between governments and politically affiliated non-profits. The organiser of a neighbourhood community association voiced the following complaint: 'Political polarisation divides society and, consequently, affects mutual trust between organisations and the trust between citizens and organisations as well.' This view was confirmed by a local service centre serving the deaf, which stated that: 'Political affiliation divides the community.' Political interference was mentioned less by the interviewees from the two cities in Taiwan.

\section{Implications for the greater China region}

It can be inferred from the cases of Hong Kong and Taiwan that CBOs in the greater China region differ from those of the West due to the historical and political development of the region. The transition from NPM to collaborative governance in China is changing the role of contracting non-profits in social service provision: how can non-profits be both competitive contractors and collaborators that create consensus (Jing \& $\mathrm{Hu}$ 2017)? While the literature shows that both roles can be taken on at the same time, performance measurement of non-profits as contractors that provide social services in China does not account for collaboration and, thus, creates barriers to it, as found in Shanghai (Jing \& Hu 2017), Hong Kong (Lee \& Liu 2012; Liu \& Chen 2015) and Taiwan (Liu, Kuo \& Lin 2018). More importantly, non-profits' disproportionate dependence on government in greater China also deprives them of autonomy and constrains network building, thus reducing their governing capacity (Jing \& Hu 2017).

Our empirical findings on Hong Kong and Taiwan have implications for the transition from NPM to collaborative governance in China. Unlike the findings of the literature on the hollow state (Milward \& Provan 2003), in our study, CBOs in Hong Kong and Taiwan reported that they seek leadership from local government. From our open-ended questions, a discussion of leadership surfaced, and the local CBOs expressed the view that it is essential to have leadership that can coordinate different nonprofits in the community to avoid unnecessary competition and promote information sharing.

The interviews indicated that the relationship between governments and non-profits should be improved so as to increase coordination. Only about one-quarter of $\mathrm{CBOs}$ studied here have participated in 
government-led forums and consultation meetings, and only one-third have been consulted by government. In particular, a higher percentage (37 per cent) of CBOs in Hong Kong reported having representatives on local coordinating committees, than in Taiwan (13 per cent). Due to historical development, the Hong Kong Government cooperates more actively with local $\mathrm{CBO}$ s while, over the last few decades, the Taiwan Government has gradually allowed the CBOs to express their perspectives on issues through a variety of channels to accurately represent the views and demands of local residents.

Internationally, governments play leadership roles by adopting strategies to improve coordination and collaboration among service providers in order to assure the level of service especially in competitive policy environments, such as community development block grants (Agranoff \& McGuire 1998), information and communication technology platforms (Urban Institute 2012), and insurance schemes, such as the Australian National Disability Insurance Scheme (Green, Malbon, Carey, Dickinson \& Reeders 2018).

On the other hand, CBOs in Hong Kong were much less involved in public advocacy and more often relied on formal links with government. Perhaps both models have merits for the greater China region when constructing social service provision arrangements for local communities and establishing effective communication channels between governments, CBOs and local residents.

Our findings for CBOs in Hong Kong and Taiwan have implications for understanding governance capacity and service quality in local communities. The People's Republic of China's recent Five-Year Development Plan listed 'Winning the battle against poverty' as an essential policy target for the near future. In particular, the government will focus on working with cross-sector actors to improve the selfsufficiency of low-income families and assure their upward mobility. The collaborative governance models adopted and the experiences accumulated in both Hong Kong and Taiwan have important implications for this commitment.

To improve governance capacity and to facilitate collaboration and exchange among different $\mathrm{CBOs}$, the government needs to provide legitimacy to bureaucrats and $\mathrm{CBOs}$ to build their connections with actors in the communities and remove barriers to forming connections with groups from different backgrounds. For instance, block grants in 
the United States (Reingold \& Liu 2009) and Hong Kong's Community Investment \& Inclusion Fund have demonstrated that governments can create cross-sector collaboration by providing separate funds (in addition to funding to services) for facilitating collaboration-related activities (Leung 2010); this might help promote community participation through community network building.

Similarly, increasing the participation of local CBOs and neighbourhood associations in the policymaking process and ensuring fair participation through self-regulation are essential. Huther and Shah (2005: 40) argue, 'the quality of governance is thus determined by the impact of this exercise of power on the quality of life enjoyed by its citizens'. Our social network analyses reveal that the way in which institutions of governance exercise their power in local communities can influence the quality of service provisions. For instance in Hong Kong, unlike in the United States, the existing laws that govern the non-profit sector do not specify the type of political activities in which a non-profit can engage. ${ }^{1}$

Our open-ended survey also suggests that $\mathrm{CBOs}$ with a strong individual political motive diminish social capital, because they work for a political agenda rather than the needs of the community. Thus, more specific and fairer regulation of those $\mathrm{CBO}$ s can reduce the negative impacts of political machines and clientelism and ensure that the provision of social services by community actors is based on public need rather than individual politicians' political interests. More importantly, diversifying different channels for local CBOs to express their concerns and needs may also reduce the influence of the larger and more influential CBOs and, thus, reduce resource-distribution asymmetry.

\section{References}

Ackroyd, S, Kirkpatrick, I \& Walker, RM 2007, 'Public management reform in the UK and its consequences for professional organization: a comparative analysis', Public Administration, vol 85, no 1, pp 9-26, doi.org/10.1111/ j.1467-9299.2007.00631.x.

1 US regulations for 501(c)(3) charity non-profits require them not to participate in any campaign activity for or against political candidates. Political non-profits, however, can file claims under 501(c)(4) and 501(c)(6). 
Agranoff, R \& McGuire, M 1998, 'Multinetwork management: collaboration and the hollow state in local economic policy', Journal of Public Administration Research and Theory, vol 8, no 1, pp 67-91, doi.org/10.1093/oxfordjournals. jpart.a024374.

Ansell, C 2003, 'Community embeddedness and collaborative governance in the San Francisco Bay Area', in M Diani \& D McAdam (eds), Social Movements and Networks: Relational Approaches to Collective Action, Oxford University Press, Oxford, New York, doi.org/10.1093/0199251789.003.0006.

Berry, JM, Portney, KE \& Thomson, K 1993, The Rebirth of Urban Democracy, Urban Institute Press, Washington, DC.

Centre for Civil Society and Governance 2010, 'Serving alone: the social service sector in Hong Kong', Annual Report on the Civil Society in Hong Kong 2009, The University of Hong Kong.

Chaskin, RJ 2001, 'Building community capacity: a definitional framework and case studies from a comprehensive community initiative', Urban Affairs Review, vol 36, no 3, pp 291-323, doi.org/10.1177/10780870122184876.

Chaskin, RJ \& Greenberg, DM 2015, 'Between public and private action: neighborhood organizations and local governance', Nonprofit and Voluntary Sector Quarterly, vol 44, no 2, pp 248-67, doi.org/10.1177/0899764 013510407.

Christensen, T \& Lægreid, P 2001, 'New public management: the effects of contractualism and devolution on political control', Public Management Review, vol 3, no 1, pp 73-94, doi.org/10.1080/14616670010009469.

Crenson, M 1983, Neighborhood Politics, Harvard University Press, Cambridge, Massachusetts, doi.org/10.4159/harvard.9780674188112.

Emerson, K, Nabatchi, T \& Balogh, S 2012, 'An integrative framework for collaborative governance', Journal of Public Administration Research and Theory, vol 22, no 1, pp 1-29, doi.org/10.1093/jopart/mur011.

Ferlie, E, Ashburner, L, Fitzgerald, L \& Pettigrew, A 1996, The New Public Management in Action, Oxford University Press, New York, doi.org/10.1093/ acprof:oso/9780198289029.001.0001.

Freeman, L 1979, 'Centrality in social networks: conceptual clarification', Social Networks, vol 1, pp 215-39, doi.org/10.1016/0378-8733(78)90021-7.

Galaskiewicz, J 1979, Exchange Networks and Community Politics, Sage Publishing House, Beverly Hills, California. 
Granovetter, M 1985, 'Economic action and social structure: the problem of embeddedness', American Journal of Sociology, vol 91, no 3, pp 481-510, doi.org/10.1086/228311.

Green, C, Malbon, E, Carey, G, Dickinson, H \& Reeders, D 2018, Competition and Collaboration between Service Providers in the NDIS, Centre for Social Impact, UNSW Sydney.

Grønbjerg, KA \& Salamon, LM 2002, 'Devolution, marketization, and the changing shape of government-nonprofit relations', in LM Salamon (ed), The State of Nonprofit America, Brookings Institution Press, Washington, DC.

Gruening, G 2001, 'Origin and theoretical basis of new public management', International Public Management Journal, vol 4, no 1, pp 1-25, doi.org/ 10.1016/S1096-7494(01)00041-1.

Gulati, R \& Gargiulo, M 1999, 'Where do interorganizational networks come from?', American Journal of Sociology, vol 104, no 5, pp 1439-93, doi.org/ $10.1086 / 210179$.

Hood, C 1995, "The "new public management" in the 1980s: variations on a theme', Accounting, Organizations and Society, vol 20, no 2-3, pp 93-109, doi.org/10.1016/0361-3682(93)E0001-W.

Hunter S \& Ritchie, P 2007, Co-production and Personalisation in Social Care: Changing Relationships in the Provision of Social Care, Jessica Kingsley Publishers, London.

Huther, J \& Shah, A 2005, 'A simple measure of good governance', in A Shah (ed), Public Services Delivery, The World Bank, Washington, DC.

Jing, Y \& Hu, Y 2017, 'From service contracting to collaborative governance: evolution of government non-profit relations', Public Administration and Development, vol 37, pp 191-202, doi.org/10.1002/pad.1797.

Kettl, DF 2006, 'Managing boundaries in American administration: the collaboration imperative', Public Administration Review, vol 66, no 1, pp 10-19, doi.org/10.1111/j.1540-6210.2006.00662.x.

Kramer, RM 1981, Voluntary Agencies in the Welfare State, University of California Press, Berkeley.

Kuan, YY, Lee, YH \& Hsieh, LY 2006, 'The governance of communitybased foundations in Taiwan: the comparative study between Hsin-Kong Foundation and Yang-Sun Foundations', Journal of Public Administration, vol 18, pp 21-25 [in Chinese], doi.org/10.1177/095207670602100303. 
Lee, EWY 2005, 'Nonprofit development in Hong Kong: the case of a statistcorporatist regime', VOLUNTAS: International Journal of Voluntary and Nonprofit Organizations, vol 16, no 1, pp 51-68, doi.org/10.1007/s11266005-3232-z.

Lee, EWY \& Liu, HK 2012, 'Factors influencing network formation among social service nonprofit organizations in Hong Kong and implications for comparative and China studies', International Public Management Journal, vol 15, no 4, pp 454-78.

Leung, J 2010, 'Social capital and community: a review of international and Hong Kong development', in SH Ng, SY Cheung, \& B Praksah (eds), Social Capital in Hong Kong: Connectivities and Social Enterprises, City University of Hong Kong.

Lin, XT, Chuang, LH, Liu, SJ \& Hwang, YS 2012, 'Making the community work: the correlation between social capital and community participation', Taiwanese Journal Social Welfare, vol 10, no 2, pp 161-210 [in Chinese].

Liu, HK 2019, 'The impact of transition from British to Chinese rule on social service delivery systems in Hong Kong', Policy \& Politics, vol 47, no 2, pp 331-52, doi.org/10.1332/030557318X15407316999851.

Liu, HK \& Chen, B 2015, 'The challenges of implementing collaborative governance in Hong Kong: case study of a low-income family community', in Y Jing (ed), The Road to Collaborative Governance in China, Palgrave Macmillan, New York, doi.org/10.1057/9781137542182_3.

Liu, LC, Kuo, HW \& Lin, CC 2018, 'Current status and policy planning for promoting age-friendly cities in Taitung County: dialogue between older adults and service providers', International Journal of Environmental Research and Public Health, vol 15, no 10, pp 2314-40.

Marwell, NP 2004, 'Privatizing the welfare state: nonprofit community-based organizations as political actors', American Sociological Review, vol 69, no 2, pp 265-91, doi.org/10.1177/000312240406900206.

_ 2009, Bargaining for Brooklyn, University of Chicago Press.

Meyer, M \& Zucker, L 1989, Permanently Failing Organizations, Sage Press, Newbury Park.

Milward, HB \& Provan, K 2003, 'Managing the hollow state collaboration and contracting', Public Management Review, vol 5, no 1, pp 1-18, doi.org/ 10.1080/1461667022000028834. 
Mosley, JE 2011, 'Institutionalization, privatization, and political opportunity: what tactical choices reveal about the policy advocacy of human service nonprofits', Nonprofit and Voluntary Sector Quarterly, vol 40, no 3, pp 435-57, doi.org/10.1177/0899764009346335.

Nadash, P \& Shih, YC 2013, 'Introducing social insurance for long-term care in Taiwan: key issues', International Journal of Social Welfare, vol 22, no 1, pp 69-79, doi.org/10.1111/j.1468-2397.2011.00862.x.

Osborne, D \& Gaebler, T 1993, Reinventing Government: How the Entrepreneurial Spirit is Transforming the Public Sector, Penguin, New York.

Osborne, S 2006, 'The new public governance?', Public Management Review, vol 8, no 3, pp 377-87, doi.org/10.1080/14719030600853022.

Ostrander, SA 2013, 'Agency and initiative by community associations in relations of shared governance: between civil society and local state', Community Development Journal, vol 48, no 4, pp 511-24, doi.org/10.1093/cdj/bss051.

Painter, M 2005, 'Transforming the administrative state: reform in Hong Kong and the future of the developmental state', Public Administration Review, vol 65, no 3, pp 335-46, doi.org/10.1111/j.1540-6210.2005.00458.x.

Pollitt, C \& Bouckaert, G 2000, Public Management Reform: A Comparative Analysis, Oxford University Press.

Powell, W 1990, 'Neither market nor hierarchy: network forms of organization', Research in Organizational Behavior, vol 12, pp 295-336.

Provan, KG \& Milward, HB 1991, 'Institutional-level norms and organizational involvement in a service-implementation network', Journal of Public Administration Research and Theory, vol 1, no 4, pp 391-418.

1995, 'A preliminary theory of interorganizational network effectiveness: a comparative study of four community mental health systems', Administrative Science Quarterly, vol 40, no 1, pp 1-33, doi.org/10.2307/2393698.

Putnam, RD 1993, Making Democracy Work: Civic Traditions in Modern Italy, Princeton University Press, doi.org/10.2307/j.ctt7s8r7.

Reingold, DA \& Liu, HK 2009, 'Do poverty attitudes of social service agency directors influence organizational behavior?', Nonprofit and Voluntary Sector Quarterly, vol 38, no 2, pp 307-32, doi.org/10.1177/0899764008316967.

Salamon, LM 1997, Holding the Center: America's Nonprofit Sector at a Crossroads, New York, Nathan Cummings Foundation. 
Smith, SR \& Lipsky, M 1993, Nonprofits for Hire: The Welfare State in the Age of Contracting, Harvard University Press, Cambridge, Mass.

Urban Institute 2012, The Community Platform: Engagement, Analysis, and Leadership Tools, Washington, DC.

Uzzi, B 1996, 'The sources and consequences of embeddedness for the economic performance of organizations: the network effect', American Sociological Review, vol 61, pp 674-98, doi.org/10.2307/2096399.

Wu, YQ 2011, 'Review and prospect of long term care policy for the elderly in Taiwan: federation for the welfare of the elderly's perspective', Community Development Journal, vol 136, pp 251-63.

Wang, GX 2016, 'Exploration of the relationship between the service delivery quality of Community Care Stations and successful aging: the moderation of cognition on government role', Journal of Public Administration, vol 50, pp 77-115 [in Chinese].

Wang, ST 2013, 'The coordination of nonprofit organizations in community care service: a research for the Community Care Stations', NTU Social Work Review, vol 27, pp 185-228.

Wasserman, S \& Faust, K 1994, Social Network Analysis: Methods and Applications, Cambridge University Press, New York, doi.org/10.1017/ CBO9780511815478.

White, HC, Boorman, SA \& Breiger, RL 1976, 'Social structure from multiple networks. I. Blockmodels of roles and positions', American Journal of Sociology, vol 81, no 4, pp 730-80, doi.org/10.1086/226141.

Xian, XP, Kuan, YY \& Lu, WP 2009, Nonprofit Sector: Organization and Operation, Chuliu Press, Taipei [in Chinese].

Yin, RK 2004, Case Study Research: Design and Methods, Sage, Los Angeles. 
This text is taken from Designing Governance Structures for Performance and Accountability: Developments in Australia and Greater China, edited by Andrew Podger, Tsai-tsu Su, John Wanna, Hon S. Chan and Meili Niu, published 2020 by ANU Press, The Australian National University, Canberra, Australia.

doi.org/10.22459/DGSPA.2020.08 